NASA Technical Memorandum 83641

\title{
Supersonic STOVL Ejector Aircraft from a Propulsion Point of View
}

R. Luidens, R. Plencner, W. Haller, and A. Glassman Lewis Research Center

Cleveland, Ohio

Prepared for the

Twentieth Joint Propulsion Conference cosponsored by the AIAA, SAE, and ASME Cincinnati, Ohio, June 11-13, 1984

\section{N/SA}




\section{SUPERSONIC STOVL EJECTOR AIRCRAFT}

FROM A PROPULSION POINT OF VIEW

R. Luidens,* R. Plencner, ** W. Haller, ** and A. Glassmant

National Aeronautics and Space Administration

Lewis Research Center

cleveland, Ohto

\section{Abstract}

The paper first describes a baseline supersonic stovl ejector aircraft, including its propulsion and typical operating modes, and identifies important propulsion parameters Then a number of propulsion system changes are evaluated in terms of improving the lift-off performance; namely, aft deflection of the ejector jet and heating of the ejector primary air efther by burning or using the hot engine core flow. The possibility for cooling the footprint is tllustrated for the cases of mixing or interchanging the fan and core flows, and using a core flow ejector Finally, the application of a new engine concept is presented, the turbine bypass engine plus a turbocompressor to supply the ejector primary air, and thrust during takeoff and combat

\section{Introduction}

It is generally accepted that short takeoff and vertical landing (STOVL) aircraft have an important place in the military The British bullt Harrier, a subsonic aircraft, is used by Britain, Spain, India, and the US. Marines The Russians also have a subsonic VTOL aircraft, the Forger, for use on small aircraft carriers

The next generation of STOVL aircraft is expected to have at least supersonic dash capability There are many candidate configurations for a follow-on alrcraft, but four of the leading contenders ${ }^{1}$ are shown in figures 1 and 2 They are: (1) the Remote Augmented Lift System (RALS) (which is taken to include the turbine bypass engine with turbocompressor unit), 2,3 (2) the Tandem or Hybrid Fan, 4 (3) the Ejector, and (4) the Deflected Thrust system, such as, an advanced Harrier with fan air burning

The present paper deals with the Ejector configuration, 5 and in particular its propulsion system. The configuration to be discussed, shown in figure 2, has a delta wing with foldable ejectors through the wing adjacent to the fuse lage

In considering the propulsion system for an advanced STOVL alrcraft, there are several important characteristics to be considered which form the outline for the paper

\footnotetext{
*Deputy Chief, Advanced Programs and Planning office, Associate Fellow AIAA. **Aerospace Engineer

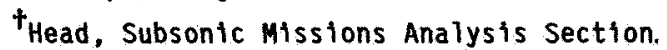

1 Higher propulsion system thrust for greater 11ft-off acceleration.

2. Cooler footprint, for safer, more convenient handling, and lower observability.

\section{Alternative basic propulsion cycles}

The approach of this paper is to use the aircraft of reference 5 as a baseline, and then to consider some candidate propulsion system growth options The vehicle described in reference 5 was selected on the basis of detalled aircraft design and performance analyses The present paper analyses the propulsion system options from a fundamental point of view and does not involve detailed design or the evaluation of such factors as weights, aircraftpropulsion integration, and costs Any selection from the candidate growth options will depend on further detailed studies

\section{Baseline Ejector Alrcraft}

The baseline ejector alrcraft and propulsion system is described first

\section{Ejector Types}

Even having picked an ejector type aircraft there are five types of ejectors listed on the left side of figure 3 that could be considered They fall into two categories: those with modest primary pressure ratios and subsonic secondary flow, and those with a high primary pressure ratio. Those with the modest primary pressure ratio are: (1) those with steady flow and fixed primary nozzles, (2) those with low speed rotating primary nozzles, and (3) those with pulsed flow primaries Those with the high primary pressure ratio are: (4) those having supersonic secondary flow, and (5) two stage ejectors Diffuser blowing for greater diffusion ratio or rate and acoustic enhancement of mixing might be used with any of these. The present study deals with only the first type.

Based on detalled analyses and experiments for this type of ejector, the geometric characteristics shown on the right of figure 3 were selected as giving good ejector performance or a high augmentation ratio: (a) a 18.1 ejector exit to throat area ratio, and (b) a diffuser wall half angle of 8 degrees This yields a secondary to primary mass flow ratio, $m_{s} / m_{p}$. of about 10 for equal primary and secondary flow densities, and an augmentation ratio, $\varphi_{\mathrm{ej}}$, of about 17 . 
Even with a high subsonic throat Mach number, the thrust per volume of the ejector is low and the drag associated with its volume is generally inconsistent with supersonic flight This problem is overcome by assuming the ejector walls are foldable to eliminate the diffuser volume. A key performance parameter of the ejector then becomes the thrust per throat area For the case of the ejector in the wing, a large value reduces the hole size that must be cut through the wing

\section{Aircraft Operation}

Because the purpose of the paper is to discuss the propulsion system, it is important to review how it operates during a typical flight This is illustrated in figure 4

STO Ground Run, sketch 1: For the short take-off, e.g, 400', the core air is directed rearward, and the fan atr is burned in the fan air aft duct and also directed rearward. This, of course, is to achieve maximum axial acceleration. The aircraft is at near zero angle of attack, and the ejector is deployed ready for operation

STO Lift off, sketch 2; At lift off the fue 1 to the fan air burner is shut off, but a small quantity of fan air may be still exhausted rearward to keep the aft duct clear of residual fue 1 The main quantity of fan air is directed forward, by a valve, to the ejectors The ejector force must pitch the aircraft nose up to $18^{\circ}$ to $20^{\circ}$ angle of attack to generate wing lift in addition to the ejector lift The core nozzle is deflected downward about $45^{\circ}$ to provide lift and thrust to overcome the aircraft and ejector drags. This is discussed in more detail later

Subsonic Cruise, sketch 3: For subsonic crutse, both the fan flow and core flow are directed rearward The fan air is not afterburned and the engine is at part throttle The ejector is now folded in contrast to the case at takeoff

Supersonic cruise and Combat, sketch 4: The fan and core jets are directed rearward, and the fan air is afterburned for supersonic cruise and combat

Vertical Landing, sketch 5: The fan is ducted to the ejector whose jet is $90^{\circ}$ to the aircraft longitudinal axis, and the core air is also deflected down $90^{\circ}$ A higher deflection may be needed during approach to aid in alrcraft deceleration. The ejector ram drag is helpful in this case

\section{Basic Ejector Propulsion Parameters}

We begin with a discussion of some basic ejector propulsion system parameters relevant to the baseline ejector alrcraft and ejector aircraft in general before discussing some potential growth system options

Three propulsion system parameters of importance to a supersonic ejector aircraft are: (1) the ejector thrust per unit throat area, (2) the ejector thrust per unit fan plus ejector ducting frontal area, and (3) the thrust per unit volume of the propulsion system. Each of these will be discussed

\section{Thrust Per Ejector Throat Area}

Figure 5 shows a typical ejector layout in a delta wing. The purpose of this ejector is two fold: (1) to augment the basic fan thrust (the fan flow is the ejector primary flow) to provide $11 \mathrm{ft}$, and (2) to provide an alrplane nose-up pitching moment about the aircraft center of gravity (c.g.) for aircraft trim.

The ejector throat area to wing area ratio, $A_{t} / S_{w}$, is related to other aircraft and engine characteristics by the relation

$$
\begin{aligned}
\left(A_{t} / S_{W}\right)= & \left(W_{G} / S_{W}\right) \quad\left(F_{t o t} / W_{G}\right) \\
& \left(F_{\mathrm{fn}} / F_{t o t}\right) \\
& \left(1 / F_{e j} / A_{t}\right)
\end{aligned} \varphi_{0}
$$

The terms in this relation are defined below and typical values are listed

Term:

Typical Value:

$$
\begin{aligned}
& W_{G} / S_{W}=\begin{array}{l}
\text { aircraft wing } \\
\text { loading, lbs/ft } 2
\end{array} \\
& F_{\text {tot }} / W_{G}=\begin{array}{l}
\text { aircraft thrust } \\
\text { loading }
\end{array} \\
& F_{f n} / F_{t o t}=\begin{array}{l}
\text { fan to total thrust } \\
\text { split }
\end{array} \\
& \varphi_{0} \equiv F_{e j} / F_{f n}=\begin{array}{l}
\text { overall ejector } \\
\text { augmentation ratio }
\end{array} \\
& F_{e j} / A_{t}=\begin{array}{l}
\text { ejector thrust to throat } \\
\text { area ratto, } 1 \mathrm{bs} / \mathrm{ft} 2
\end{array} \\
& A_{t} / S_{W}=\begin{array}{l}
\text { ejector throat to wing } \\
\text { area ratio }
\end{array}
\end{aligned}
$$

This relation shows that a high ejector thrust per unit of ejector throat area, $F_{e j} / A_{t}$, will reduce the area cut through the wing structure $A_{t} / S_{W}$. A reduced ejector throat area will also permit the moment arm to the center of the ejector thrust, $x_{c q}$, to increase, thus increasing the ejector pitching moment capability

Figure 6 shows the results of a simple anal. ysis of a steady flow ejector Figure 6 a shows that higher thrusts per unit throat area are achieved by high, subsonic, secondary flow throat Mach numbers

Figure $6 \mathrm{~b}$ relates the secondary flow throat Mach number to the ejector primary pressure ratio and temperature Increasing the primary pressure ratio, especially up to values of about 4 is important, but increasing primary flow temperature is also important The increase in secondary throat Mach number with primary gas temperature assumes the primary nozzle size increases with temperature, and that the secondary flow geometry remains constant (A later discussion considers the case of no prtmary or secondary geometry change) The dotted line, for example, shows a primary nozzle 
pressure ratio of 3 , a primary gas temperature of about $800^{\circ} \mathrm{R}$ ylelding a secondary flow Mach number of about 0.5 and a corresponding $F_{\text {ej }} / A_{t}=300 \mathrm{lbs} / \mathrm{sq} \mathrm{ft}$. In the baseline case, the ejector primary pressure is provided by the engine fan. The source of the hot primary temperature will be discussed later

The pitching moment an ejector of a given throat area will produce depends on its length to width ratio, $1 / w$. Typical results for $A_{t} / S_{w}=0.07$ are shown in figure 7 An $1 / w$ of about 3.5 yields the maximum pitching moment although the maximum is flat A larger $1 / \mathrm{W}$, say 5 , reduces the blockage that the ejector discharge causes to the free stream air flowing under the wing with iittle reduction in pitching moment from the optimum

The sketch in figures 5 and 7 has an $A_{t} / S_{w}=0.07$ and an $1 / w=5.0$.

\section{Thrust Per Fan Plus Duct Frontal Area}

For an aircraft to have supersonic capabi1. ity, a low frontal area of the aircraft, which consists in part of the propulsion system frontal area, is very important so an important propul ston system parameter is the thrust per propul sion system frontal area For the ejector system, the frontal area shown in figure 8 is made up of that part of the fan frontal area that provides the ejector air. $A_{f n}$, plus the frontal or cross sectional area of the duct, $A_{d}$, which in the assumed aircraft, passes over the fan to deliver the fan air to the ejector

The cross sectional area of the duct is determined by the mass flow in the duct, and the duct flow Mach number, $M_{d}$, which in turn is a function of the fan pressure ratio, FPR The choice of duct Mach number is also related to the total pressure losses in the duct which generally increase with the duct Mach number squared The duct losses are also proportional to the number of duct turns, which in this case is the primary source of the losses The baseline ejector system being considered has four, $90^{\circ}$ turns, 111 ustrated in figure 8 : (1) from the aft axial direction exiting the fan to upward, (2) from upward to forward in the duct passing over the fan, (3) from forward in the fuselage duct to outboard into the wing where the ejector is, and (4) from outward to downward as required to serve as the downward thrusting ejector primary.

The results of an analysis of such a system are shown in figure 9 In figure $9 a$, $\mathrm{F}_{\mathrm{ej}} /\left(\mathrm{A}_{\mathrm{fn}}+\mathrm{A}_{\mathrm{d}}\right)$ is plotted versus fan pressure ratio for several values of duct Mach number A large value of the ordinate is desirable The curves show increasing $F_{e j} /\left(A_{f n}+\right.$ Ad) with increasing fan pressure ratio for all duct Mach numbers The effect of the duct loss may be seen for $a M_{0}=02$ by comparing the dashed line, which has no losses with the solid 1 ine which has the duct turning losses included The duct Mach number optimizes between $M_{0}=0$ ? and 0.3 . Higher duct Mach numbers reduce the duct cross sectional area, which is favorable, but also increase the losses which causes a decrease the thrust, which is unfavorable. The trade-off between these two effects results in an optimum duct Mach number
Figure 9b presents the corresponding ejector thrust divided by the fan shaft energy input, $F_{\text {ej/E. A high value corresponds to a reduced }}$ fuel consumption rate. Since the takeoff and landing times are short, there is only a small quantity of fuel involved. In any case, for fan pressure ratios between 3 and 4 , there is not an important variation in $F_{\mathrm{ej}} / \mathrm{E}$ with fan pressure ratio or duct Mach number

\section{Thrust Per Propulsion Volume}

The volume taken up in the fuselage by the propulsion system is not avallable for payload or fuel, so a low volume propulsion arrangement is desirable Figure 10 shows two possible aircraft arrangements for both, the engine is near the center of the aircraft and provisions are made for the fan air collection and ducting to a forward ejector for takeoff and landing In the upper figure, in the cruise mode, the fan air is ducted to, and exhausted at the rear of the aircraft. This ducting occupies considerable fuselage volume. In the lower figure, in the cruise mode, the fan air nozzle is adjacent to the core nozzle. Alternatively, the fan and core air could be mixed and exhausted through a common nozzle near the airframe center Thts reduces the propulsion system volume, but aggravates the fuselage angles in the vicinity of the nozzles A detalled study is needed to resolve such questions

Subsequent discussions will deal with these geometric arrangements to achieve other objectives

\section{Ejector Propulsion Options}

Having presented the baseline ejector air. craft and some basic ejector propulsion para. meters, the following discussion deals with ways the propulsion system can be modified to yield greater thrust performance, a cooler footprint, or benefit from alternative propulsion cycle and then categorizes these modifications from a cycle point of view.

\section{Greater Performance}

Ejector Jet Deflection: Consider the possi. bility of improving the aircraft performance at ifft-off, figure 11 The base alrcraft at $11 \mathrm{ft}$ off conditions is shown in figure 11a The ejector jet, $F_{e j}$, is normal to aircraft longttudinal axis, $\delta=0$, and the lift-off is assumed to occur at an aircraft angle of attack, $\alpha=20^{\circ}$ The core jet, $F_{c r}$, is also deflected downward to provide both lift and thrust, and to balance the atrcraft pitching moments Variations from the baseline are shown in the other two figures Figure $11 \mathrm{~b}$ shows the ejector jet deflected rearward so $\delta=40^{\circ}$ Figure 11c shows the wing with trailing edge blowing so the desired $11 \mathrm{ft}$ coefficient can be achleved at $\alpha=0^{\circ}$

The forces on an example airplane, (selected to fllustrate the point of the discussion) i.e. lift, L; drag, D; and thrust, $F$, as a fraction of the airplane gross weight, $w$, are shown in figure 12 as a function of the forward velocity. V 
In figure 12a, 1ift-off can occur when $L / W=$ 1.0. At the lift-off velocity, about $110 \mathrm{fps}$, the wing, the ejector, and deflected core jet each provide about $1 / 3$ of the lift wing supported flight can occur at about $225 \mathrm{fps}$

The drag, figure $12 b$, is made up of the airframe drag, plus the engine core air ram drag, plus the ejector ram drag. The available thrust is made up of the core thrust from the deflected core jet and the reverse thrust of the ejector, reverse because it is blowing forward at an angle corresponding to the aircraft angle of attack, $\alpha=20^{\circ}$ A minimum level of $\mathrm{T} / \mathrm{W}$ above $D / W$, of about 0.06 , is required for aircraft axial acceleration. With no ejector deflection, $\delta=0$, and for the selected aircraft thrust to weight ratio, the margin of thrust over drag is unacceptable at $11 \mathrm{ft}$..off, $\mathrm{L} / \mathrm{W}=10$

An obvious way to improve this sttuation is to deflect the ejector jet rearward, say by $\delta$ $=40^{\circ}$, which then yields a forward thrust component equal to that which was the reverse thrust component and the same lift The margin of aircraft thrust over drag at lift-off is now significantly improved, it is about $02 \mathrm{~g} / \mathrm{s}$, a much more desirable level

The above discussion raises several questions:

1 Is the effective ejector jet angle set only by the geometry of the ejector or is it significantly effected by the external flow field at lift-off? This needs to be determined experimentally

2 Can an ejector be designed with a variable deflection capability with little loss in ejector augmentation ratio? This also requires experimental study

Another approach 1llustrated in figure $17 \mathrm{c}$ is to generate the wing 1 ift at near zero angle of attack by wing tralling edge blowing and thus eliminate the ejector reverse thrust effect However, there would still be an aircraft accel eration advantage to some aft deflection, e g., $\delta=20^{\circ}$, of the ejector jet

Ejector Primary Air Heating Plus Aft Fan Air Burning: Another way to improve the lift off performance is to heat the primary air for the ejector, see figure 13

The baseline ejector system uses unheated fan air when the ejector is used, figure $13 a$, but an aft duct burner is used at other times as described earlier in the discussion of figure 4

Before proceeding with discussing this option, it is interesting to note that in principal, primary air heating can be done with no change in ejector geometry, either primary noz. zles or secondary flow geometry This assumes that the primary nozzle pressure ratio remains constant ( $1 \mathrm{e}$, negligible total pressure loss due to combustion), that it is sufficient to choke the primary nozzle throat (generally the case), and the ejector augmentation ratio remains constant ( $1 \mathrm{e}$, the primary and secondary mixing are adequate) When the primary jet is heated by a temperature ratio of $\theta \equiv T_{b} / T_{\text {no }} b$ and the pressure ratio remains constant, the ejector primary exit Mach number remains constant, but the exit velocity $(v)$ increases by $\sqrt{\theta}$ because the speed of sound increases by $\sqrt{\theta}$ The flow density decreases by $\theta$ so the mass flow rate per unit area $(\mathrm{m})$, which is the product of velocity and density, decreases by $\sqrt{\theta}$. The primary thrust, $\mathrm{mv}$, is then independent of $\theta$ and so is the ejector thrust if the augmentation ratio remains constant In summary, increasing the primary air temperature at constant total pressure does not affect the primary or ejector thrusts, but reduces the primary mass flow rate by $\sqrt{\theta}$.

Now, if the ejector primary air temperature is increased, for example, by a factor $\theta_{\mathrm{pr}}=$ 4 , as by a burner as shown in figure 13b, the primary mass flow from the fan to the ejector is reduced to half The other half of the mass flow from the fan is assumed to discharge through the aft fan air duct, also shown in figure $13 \mathrm{~b}$, and can be augmented by burning by a ratio of 2 , corresponding to $\theta_{\text {ad }} \sim 40$. The numerical values on the figure are based on the sum of the fan and core thrusts being $100 \%$ and an example engine with a fan to core thrust split of $\mathrm{F}_{\mathrm{fn}} / \mathrm{F}_{\mathrm{cr}}=0.45$ The values in the boxes indicate the possible percent thrust augmenta. tion The example in figure $13 \mathrm{~b}$ shows a 31 percent thrust augmentation

An alternative way of heating the ejector primary air is by mixing it with the core flow, as illustrated in figure $13 \mathrm{c}$

In the limit, for the same fan to core thrust split used above, all the ejector primary air could be core flow, figure 13d The fan flow exiting the fan air nozzle can be burned, yielding a thrust augmentation of 31 percent

One of the advantages of using the core air for the ejector and in the aft duct, as in figure 13d, can be understood by considering the take. off sequence of events for acceleration down the runway, the hot core air is directed rear. ward in the aft duct The fan air is directed rearward by the lower variable deflection noz. zle The fan air can be burned The burning is initiated at the start of the ground run and continues through lift-off and transition to wingborne flight At lift..off, most of the core flow is directed to the ejector, and the burned fan flow is deflected downward by the lower variable deflection nozzle. This system avoids the burner light required at $11 \mathrm{ft}$-.off by the systems indicated by figure $13 \mathrm{~b}$, for the burning of the fan ejector primary air, and in figure 13c for the burning of the fan air exiting the variable deflection core nozzle

In comparing the options for heating the ejector primary air, fan air burning, figure $13 \mathrm{~b}$, or use of the hot core flow, figure 13d, for the present example, they both give the same thrust augmentation, but the use of the core air appears simpler from an engine point of view but not necessarily from an aircraft integration point of view.

Figure 14 presents the thrust augmentation for the ejector primary air burning option of 
figure 13b in a more general way. It presents the ejector primary air thrust augmentation ratio as a function of the burning temperature rise. The example condition for figure 13b is indicated by the circle symbol An important point from this figure is that the thrust augmentation varies like the square root of the temperature rise, that is, the initial increment of heat addition gives the larger thrust augmentation

The effect on takeoff performance of burning the primary air to $\theta_{\mathrm{pr}}=4$ in a propulsion system 1ike 13b, in an alrcraft 1ike that of figure $11 \mathrm{a}$, is shown in figure 15 At the $20^{\circ}$ lift-off angle of attack, the jet out the rear of the aircraft, which does not exist in the baseline case at 11ft-off, provides some lift which reduces the lift-off speed as shown in figure $15 \mathrm{a}$ This results in a lower drag at 1ift-off, figure 15b The aft jet also provides large amount of thrust so that the thrust over drag margin is significantly improved over the baseline case, figure $15 \mathrm{~b}$.

In summary, two techniques for improving lift-off performance have been discussed: ejector jet aft deflection at 1ift-off, and (2) heating of the ejector primary air by burning or by using engine core flow. Both offer signifi. cant 11ft-off thrust enhancement, but at the expense of increased complexity, and probably weight

Next, we will consider cooling the footprint

\section{Cooler Footprint}

One of the advantages of the baseline ejec. tor system over some of the other STOVL concepts is the cool, low velocity, front footprint generated by the ejector The subject of this discussion and figure 16 are some of the possi. bilities for reducing the temperature of the aft or core footprint of the baseline aircraft, figure $16 \mathrm{a}$

Ejector Primary Air Burning and Fan and Core Air Mixing: In the preceding section it was pointed out that if the fan air going to the ejector primary is heated by a temperature ratio of 4 , then half of the fan air is avallable for other purposes for the present purpose, the cooler primary air can be mixed with the core flow, figure $16 \mathrm{~b}$, to reduce the jet temperature from $1500^{\circ} \mathrm{F}$ to $1100^{\circ} \mathrm{F}$ This method yields improved 1ift-off performance, but also a small increase in the ejector jet temperatures for the reduction in core jet temperature

Ejector Primary From Core Jet: Another approach which was discussed in the preceeding section, figure $13 d$, which can also be used to reduce the jet temperatures, is to use the engine core jet for the ejector primary flow; and the cool, unburned fan flow for the aft jet, figure $16 \mathrm{c}$ The aft jet is now quite c0ol, $280^{\circ} \mathrm{F}$, and the ejector jet average temperature is $140^{\circ} \mathrm{F}$, compared with $1500^{\circ} \mathrm{F}$ for the original core flow, figure 16a. This gives one of the coolest arrangements

The disadvantages of this arrangement are the hot core flow ducting, and that the warmer temperatures that are now forward are more likely to be ingested by the engine inlet.

Second Ejector for the Engine core Flow: A direct approach to cooling the core flow is to add a second ejector around the core flow, figure 16d Its primary purpose is to $\operatorname{cool}^{1}$ the jet and secondarily to augment its thrust. such an ejector was discussed in reference 6 It may reduce the core temperature from $1500^{\circ} \mathrm{F}$ to $900^{\circ} \mathrm{F}$, for example.

The XFV-12A System: In this system 7 the fan and core air are first mixed, thus cooling the core flow and then the entire engine flow becomes the primary flow for ejectors so the primary temperature is further reduced by the ejector secondary flow.

Figure 17 shows how the ejector and mixed core exhaust flow temperatures vary with the ejector primary air burning temperature rise for the engine arrangement of figure 16b. As with the thrust augmentation, the initial increments in primary air burning result in the larger mixed core flow temperature reductions

In summary, the baseline ejector system has the advantage of a cool front footprint Two of the schemes discussed result in silghtly higher front footprint temperature to reduce the aft footprint Adding a second ejector on the core jet for cooling it, maintains the cool baseline front footprint temperature The XFV-12A system of mixing the fan and core flows and using all this flow as the primary flow for ejectors probably results in the lowest average temperature

\section{Propulsion Cycles}

There appears to be three categories of propulsion cycles, shown in figure 18, of primary interest for ejector propulsion systems All the engines discussed thus far are two-spool turbofan engines, figures $18 \mathrm{a}, \mathrm{b}$, and $\mathrm{c}$ Figure $18 d$ is the newest and most unique of the engine cycles

Separate Fan and Core Flow: In the baseline system, figure 18a, the fan and core flows are always separate This gives the greatest freedom to optimize the choice of fan pressure ratio and engine bypass ratio It may also require the greatest propulsion system volume in the air craft if it requires the fan air aft duct, shown in figure 10a.

An alternate arrangement that maintains separate fan and core flow is to duct all the core flow to the ejector or out the aft duct, figure $18 \mathrm{~b}$. The engine cycle must be selected to yield desirable ejector primary flow characteristics The fan air is always exhausted through a variable deflection nozzle on the underside of the aircraft, so the fan and core flows always remain separate.

Separate/Confluent fan and core flow: In this scheme, figure $18 \mathrm{c}$, the fan and core flows are separate during ejector operation, but are confluent during the takeoff ground roll, and during up-and-away operation. This system reduces the core exhaust temperature when the two stream are mixed, and reduces the propulsion system volume on the aircraft 
Its cycle optimization may be restricted by the requirement for core and fan static pressure matching during confluent operation, and the problem of low body surface angles for low supersonic drag may be aggravated

Another option is to keep the core and fan flows separate even though exhausting adjacently

The above systems all require two spool turbofan engines The following system is single spool

Turbine Bypass Engine and Turbocompressor Stage: The turbine bypass engine, references 2 and 3 , figure 18d, is a single spool engine like a turbojet, but is characterized, typically, by 15 percent compressor bleed at a compressor pressure ratio of about 16 at full throttle at takeoff or landing condition. This bleed air can be used to drive a turbocompressor unit, TC, figure 18d, which produces flow at a pressure ratio of 35 to 4.0 which in turn may be used as the primary air for the ejector When not used for the ejector, the TC jet can be used for acceleration during the ground roll and for combat maneuvers This is a relatively new concept and needs further evaluation.

\section{Concluding Remarks}

The initial discussion shows the baseline ejector aircraft prefers high pressure ratio fans, FPR $=35$ to 40 , and can benefit from an increase in primary air temperature Beyond this, there are a number of options for growth or advancement in aircraft characteristics over those of the baseline, but usually at the expense of increased complexity and possibly increased weight

Improved aircraft 1 ift-off performance can be obtained by: (1) adjustable ejector jet aft deflection and (2) ejector primary air heating by burning or the use of the hot core flow.

Cooler aft, or core, footprints can be approached in a number of ways, for example, (1) by mixing or displacing the notter core flow with the cooler fan flow, or (2) by a core air cooling ejector

The single.spool turbine bypass engine with turbocompressor unit which provides air at the desired pressure for the ejector primary and thrust for combat maneuvers is an alternative to the twin.spool fan engine

Finally, the baseline delta wing.ejector configuration is a valuable, relatively simple, starting point for many possibilities for enhanced performance, cooler footprints, and advanced engine cycles

\section{References}

1 Kidwe11, G. H, Jr and Lampkin, B A, "An Evaluation of Supersonic STOVL Technology," AIAA Paper 83-2493, Oct 1983
2 Sheridan, A. E., "The Application of Turbine Bypass Engines to High Performance V/STOVL Aircraft," AIAA Paper 83-2512, Oct, 1983

3 Franciscus, L C., "Supersonic SToVL Aircraft With Turbine Bypass/Mass Flow Amp 11fier Engines," AIAA-84-1403, June 1984

4 Zola, C L, Wilson, S L, III, and Eskie, $M_{\text {. A. }}$, "Tandem Fan Applications in Advanced STOVL Fighter Configurations," AIAA-84-1402, June 1984

5. Foley, W H, Sheridan, A E, and Smith, C $H$. "Study of Aerodynamic Technology for Single-Cruise-Engine V/STOVL Fighter/Attack Aircraft," NASA CR. 166268, Feb. 1982

6. Willis, W. S., Konarsk1, M., and Sutherland, W. $V$, "Conceptual Design, Evaluation and Research Identification for Remote Augmented Propulsive Lift Systems (RALS) with Ejectors For VTOL Aircraft," General Electric Co, Cincinnat1, OH, R82AEB315, May 1982 (NASÁ CR- 167906)

7. Braden, $R$ P., Nagaraja, $K S$, and Von Ohain, $H$ J $P$, "Proceedings: Ejector Workshop for Aerospace Applications," AFWAL-TR..82-3059, June 1982 

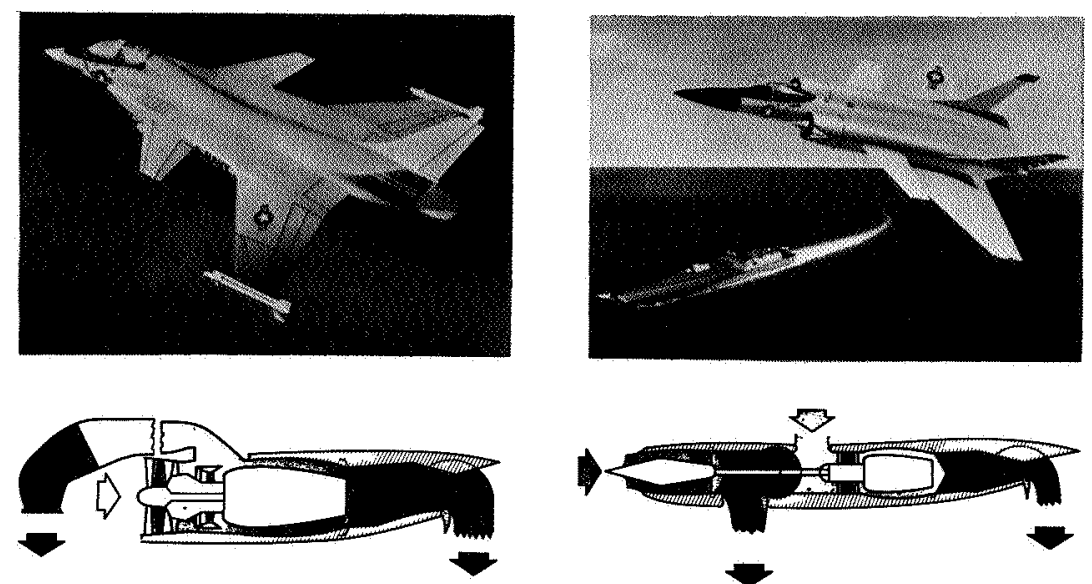

REMOTE AUGMENTED LIFT SYSTEM

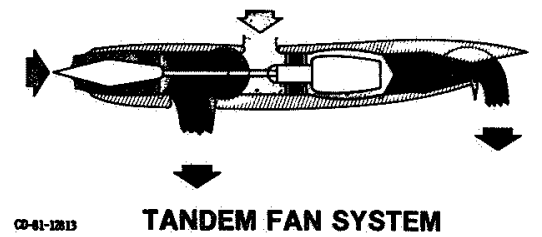

Figure 1. - Supersonic STOVL propulsion. C-82-1659
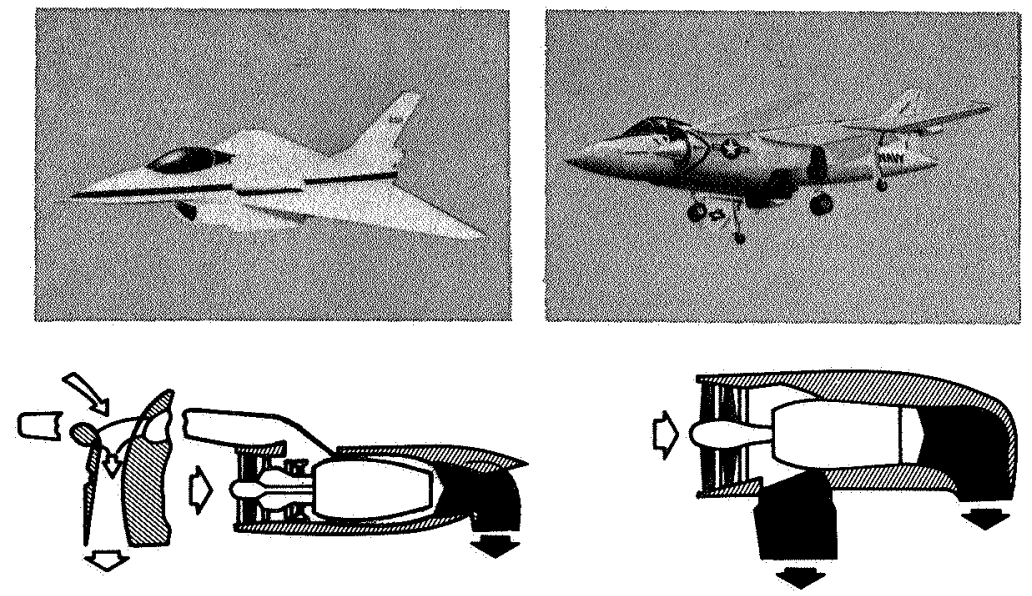

EJECTOR SYSTEM CD-82-12948 DEFLECTED THAUST SYSTEM

Figure 2. - Supersonic STOVL propulsion. $\quad$ C-82-1658 


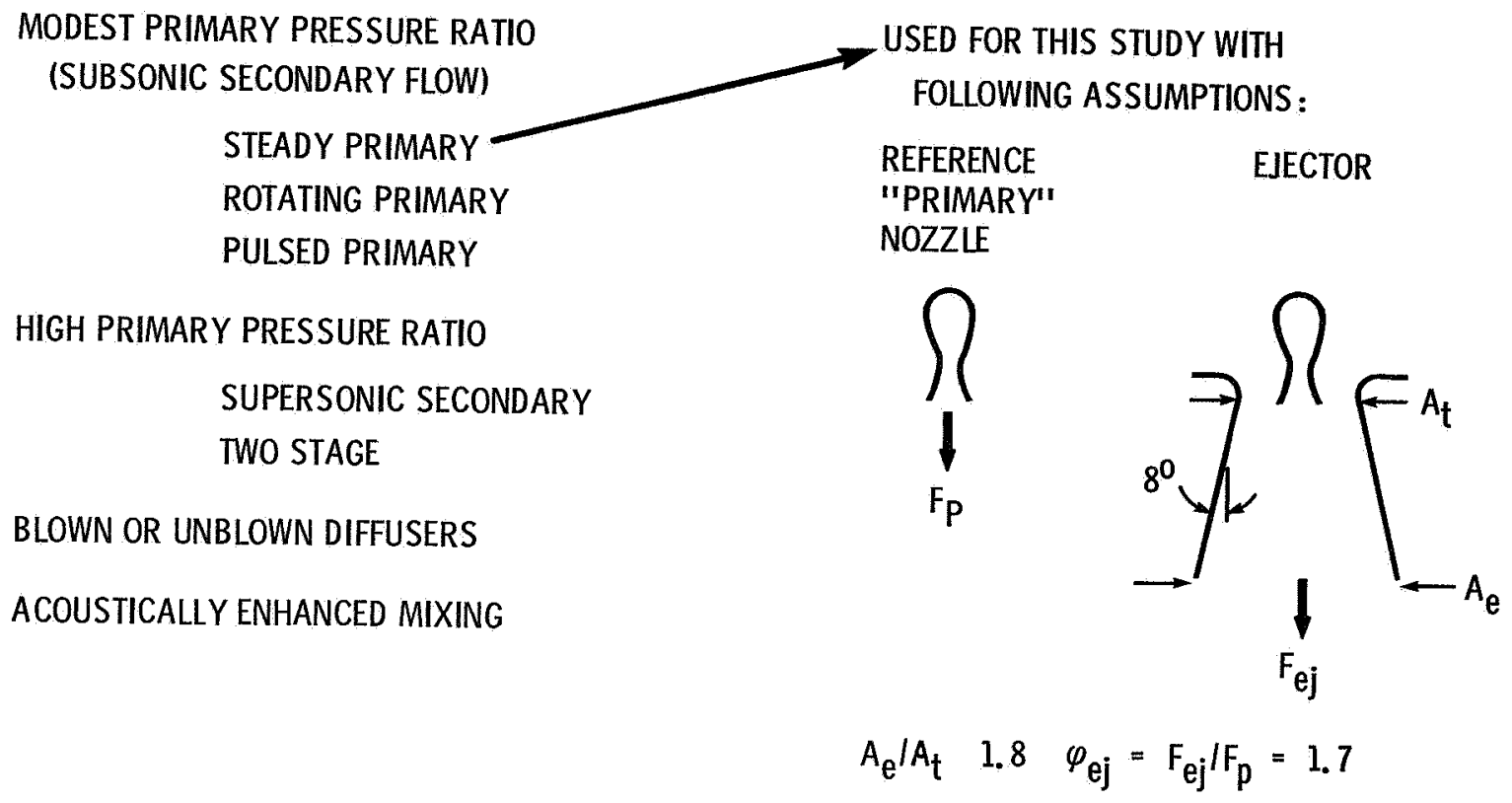

Figure 3. - Ejector types.

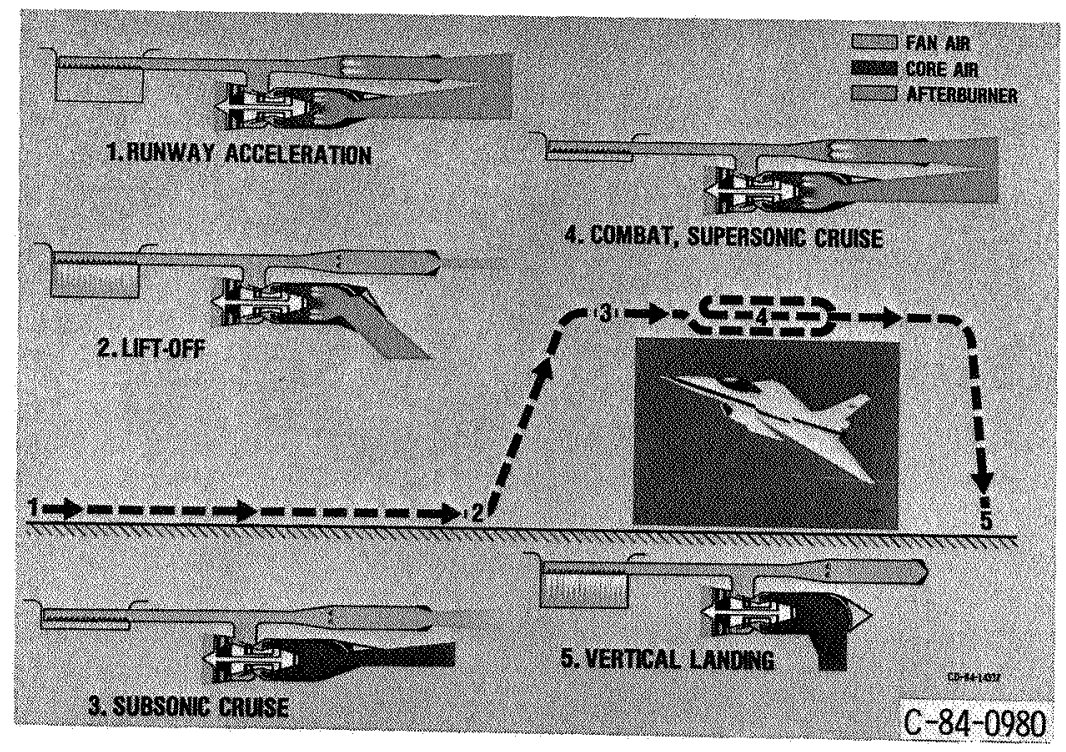

Figure 4. - Ejector propulsion modes for super sonic STOVL. 


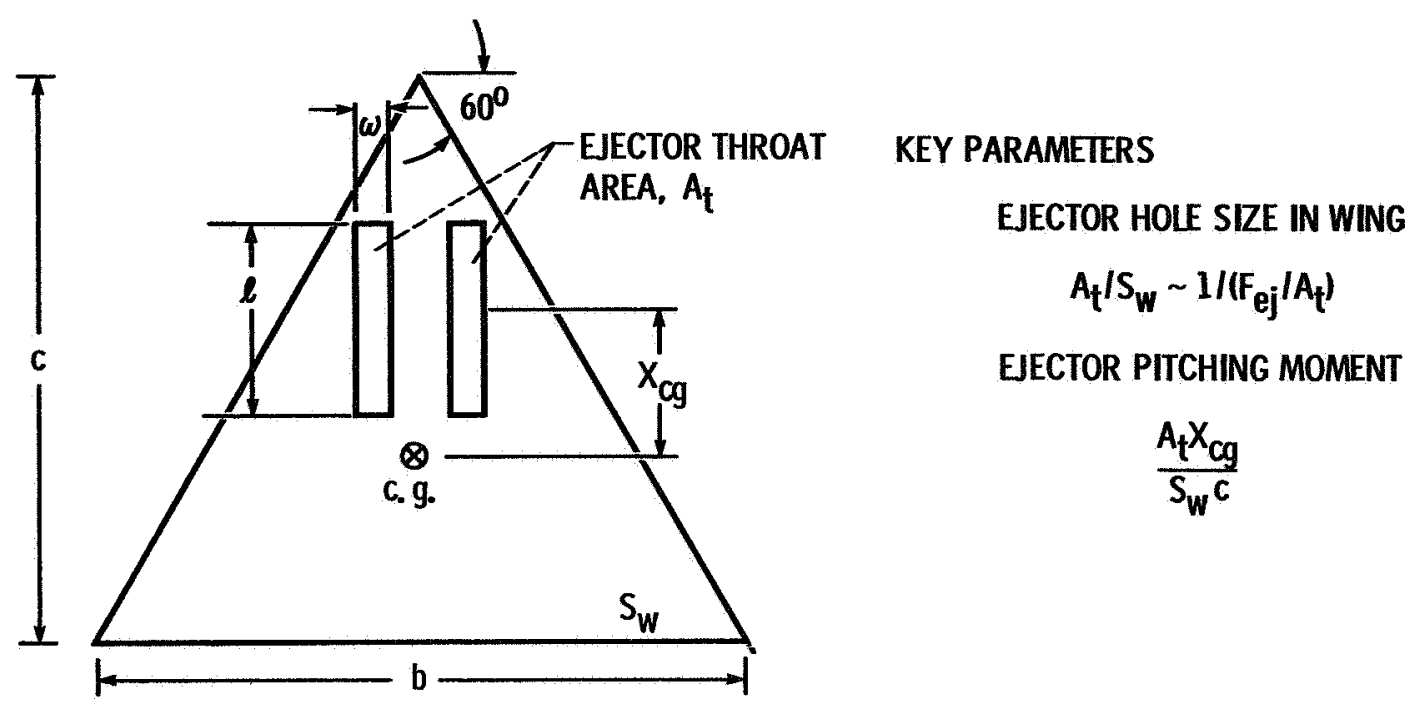

Figure 5. - Ejector and wing geometries.
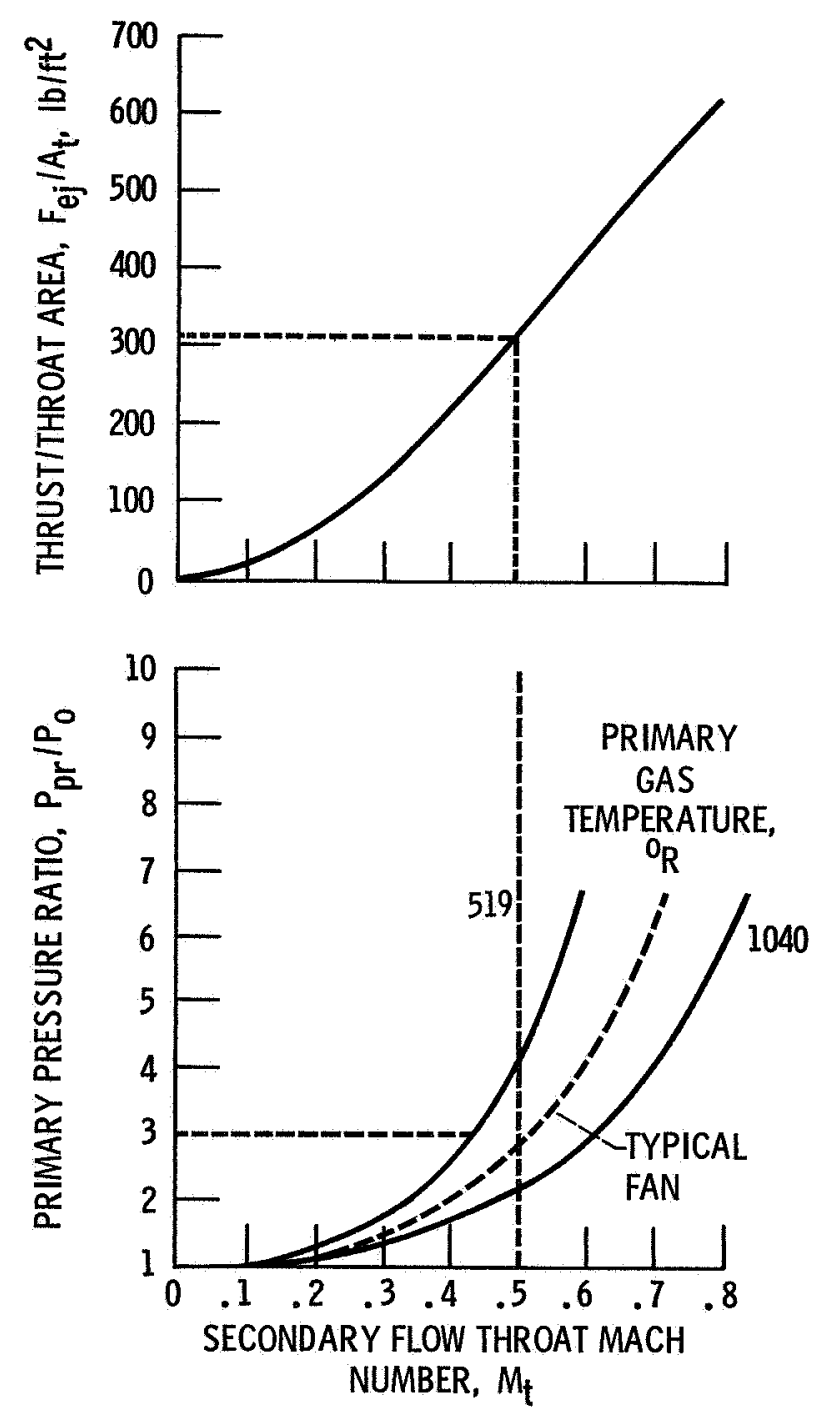

Figure 6. - Ejector thrust per thoat area. Sea level static conditions. 


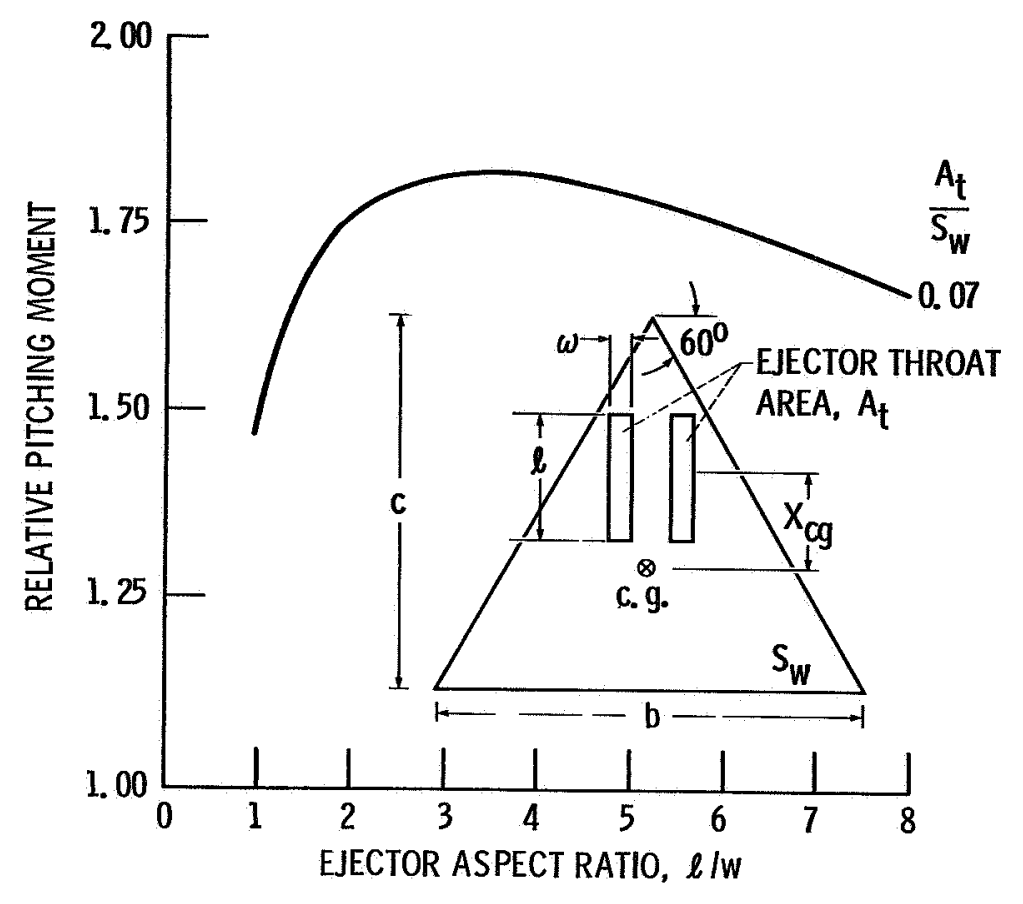

Figure 7. - Ejector pitching moments.

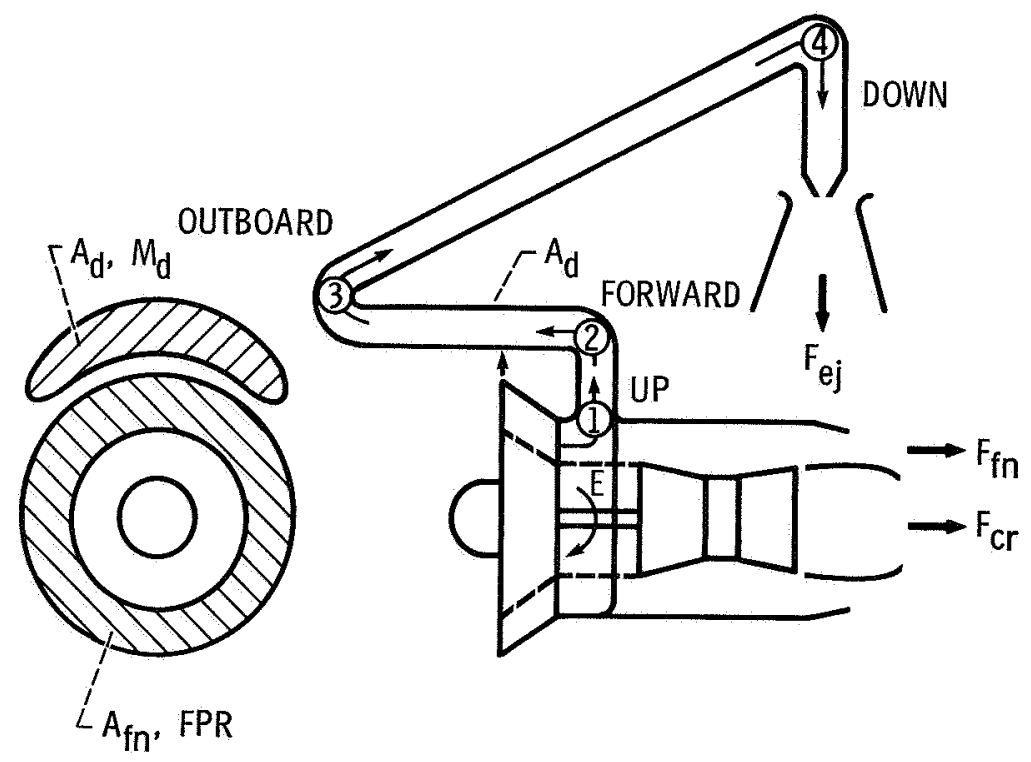

Figure 8. - Ejector propulsion system parameters. 

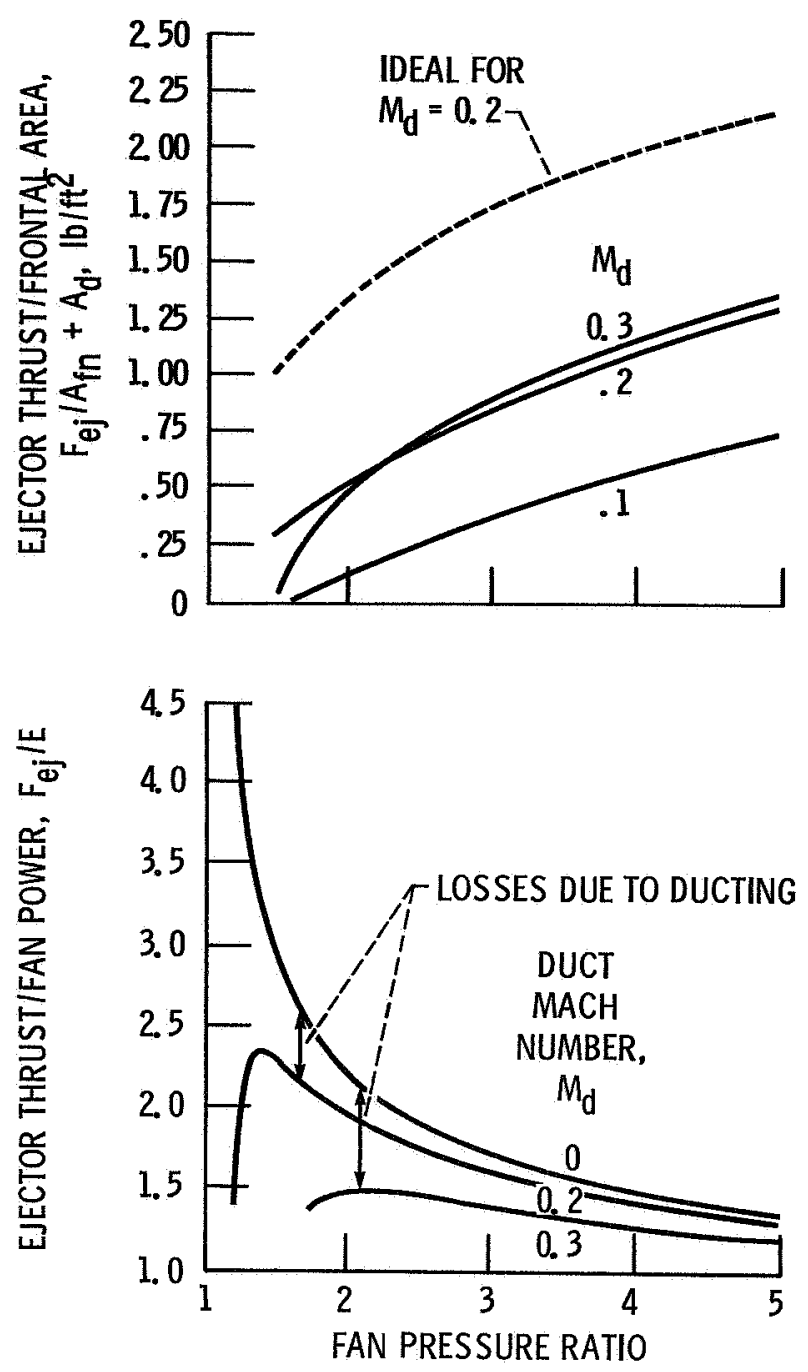

Figure 9. - Ejector thrust per frontal area and fan power input

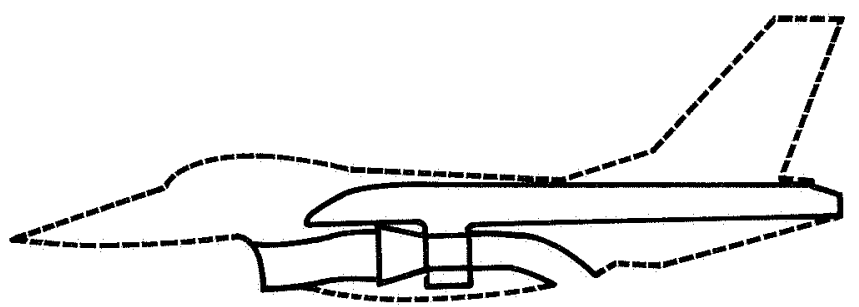

(a) Fan air exhausted at rear of aircraft.

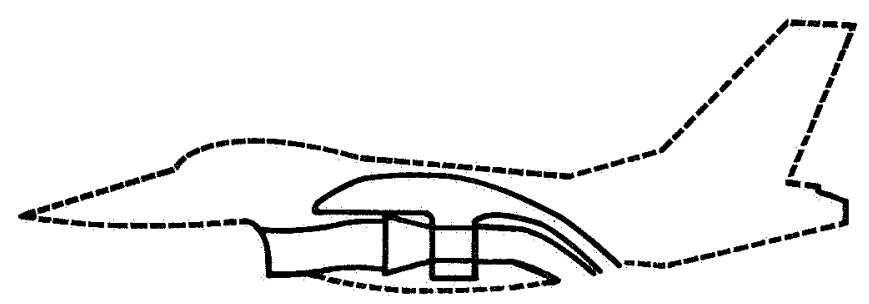

(b) Fan air exhausted adjacent to core nozzle.

Figure 10. - Effect of fan air ducting on available fuselage volume. 

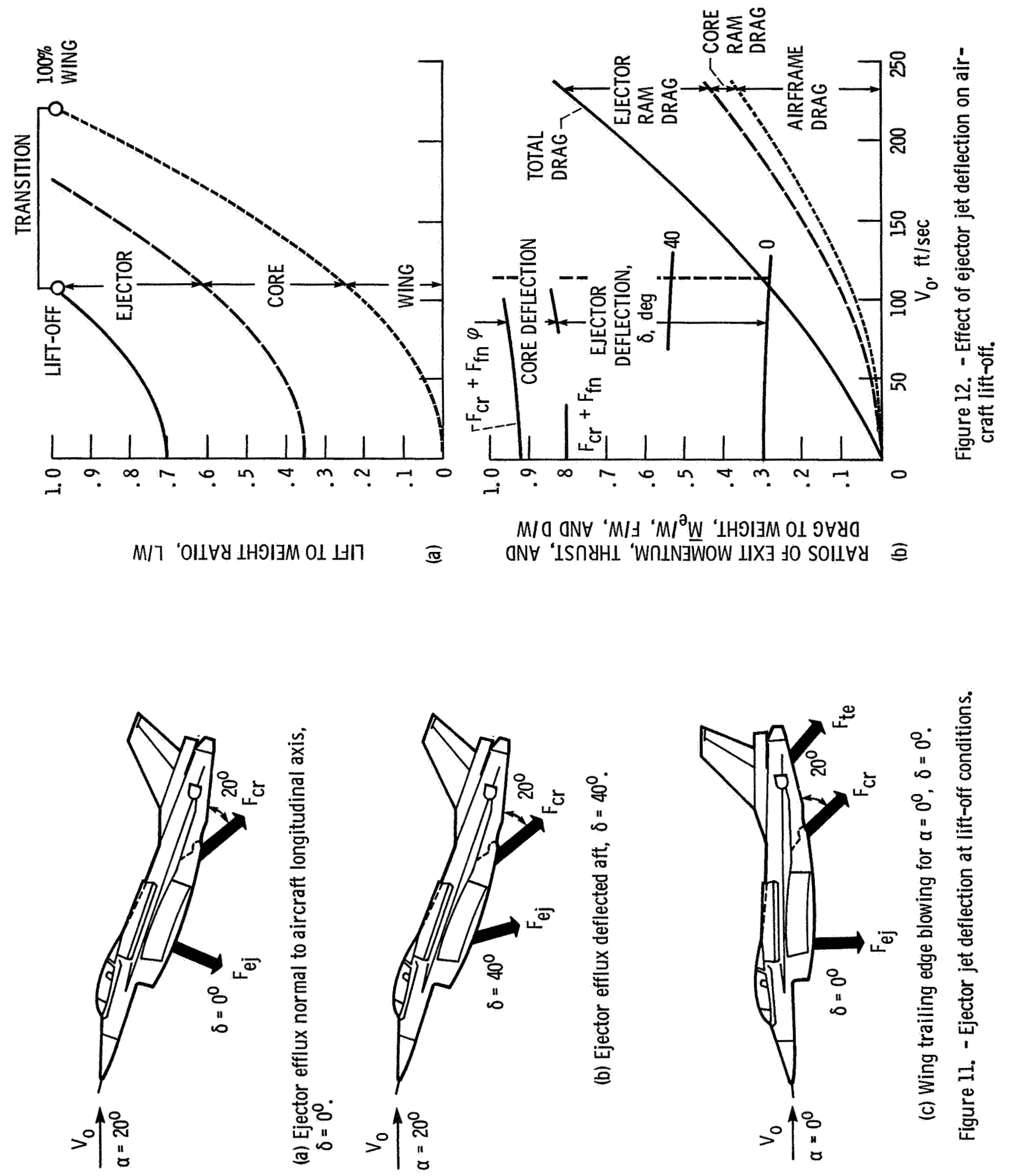


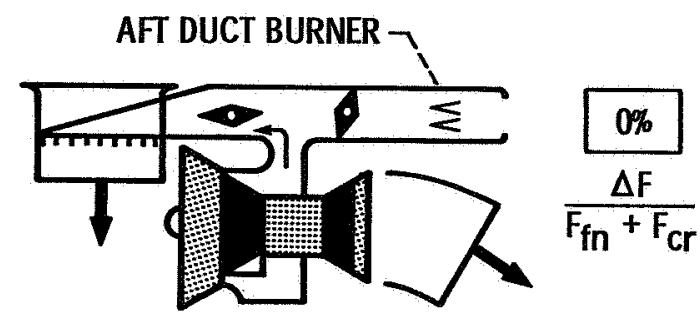

(a) Baseline, cool fan flow to ejector.

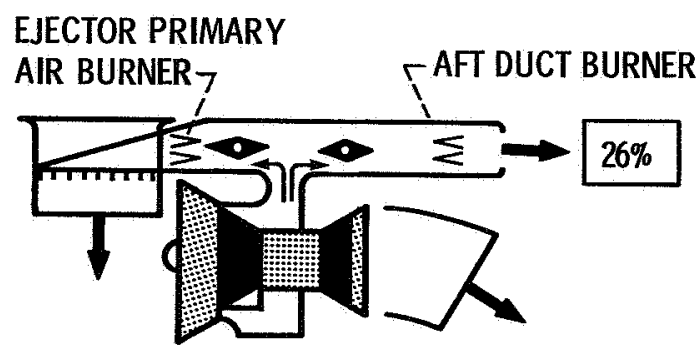

(b) Burned fan flow to ejector.

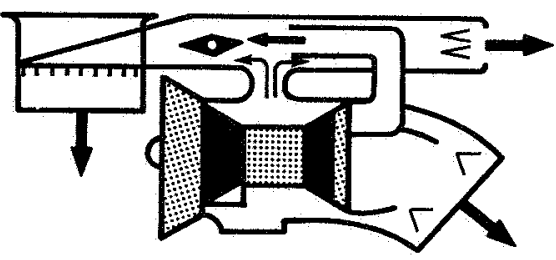

(c) Mixed cool fan flow and hot core flow to ejector.

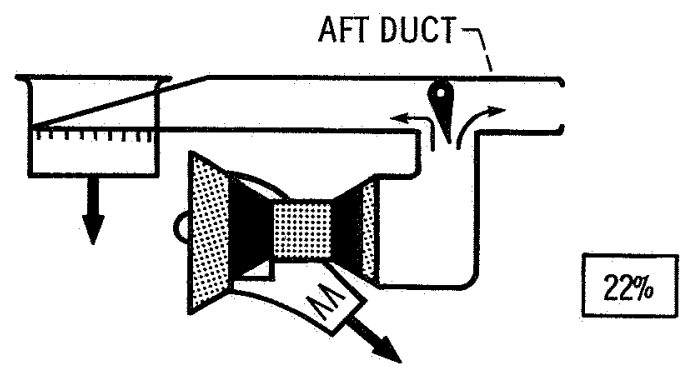

(d) All core flow to ejector.

Figure 13. - Ejector primary air heating options at lift-off conditions. 


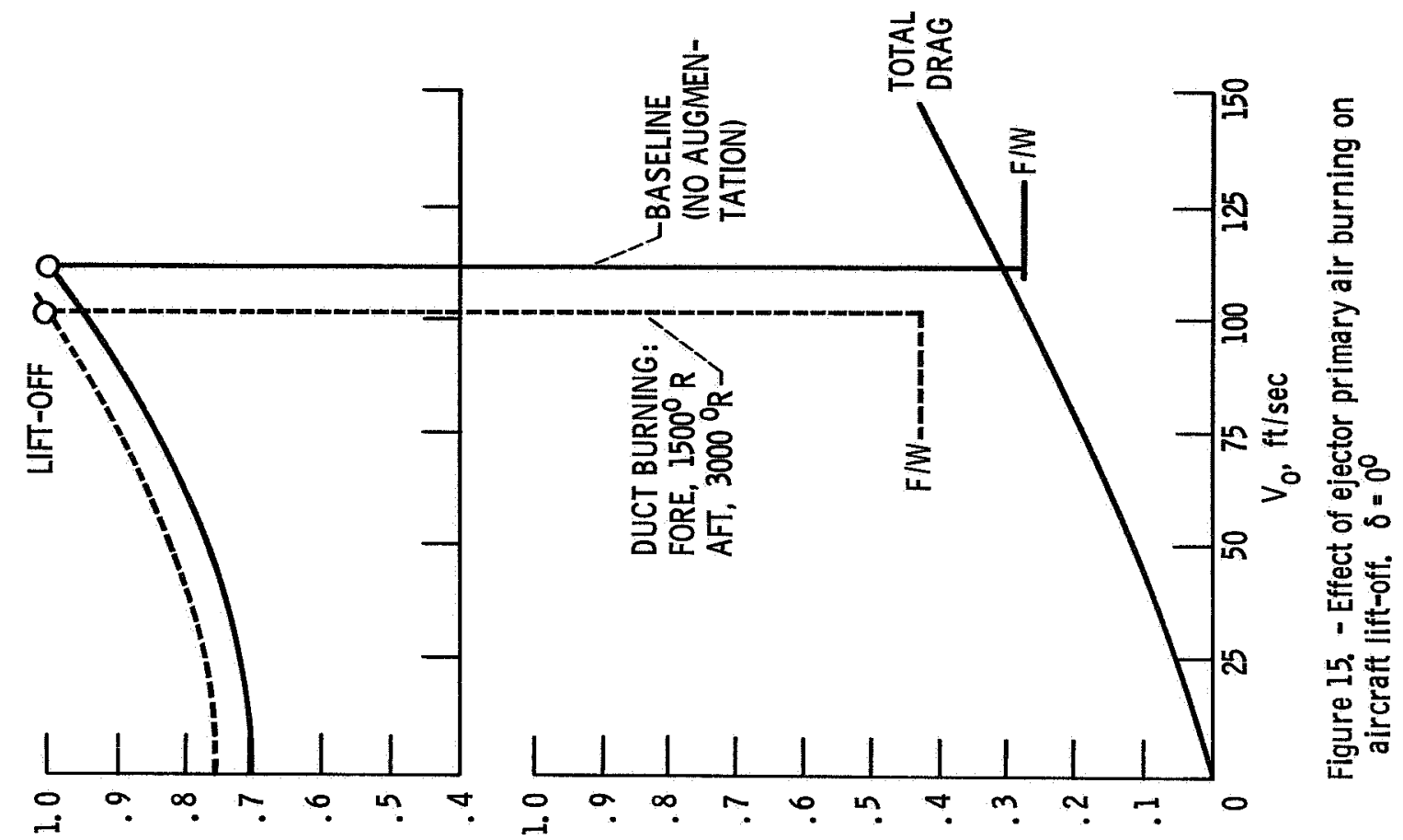

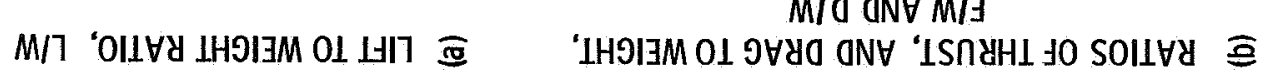

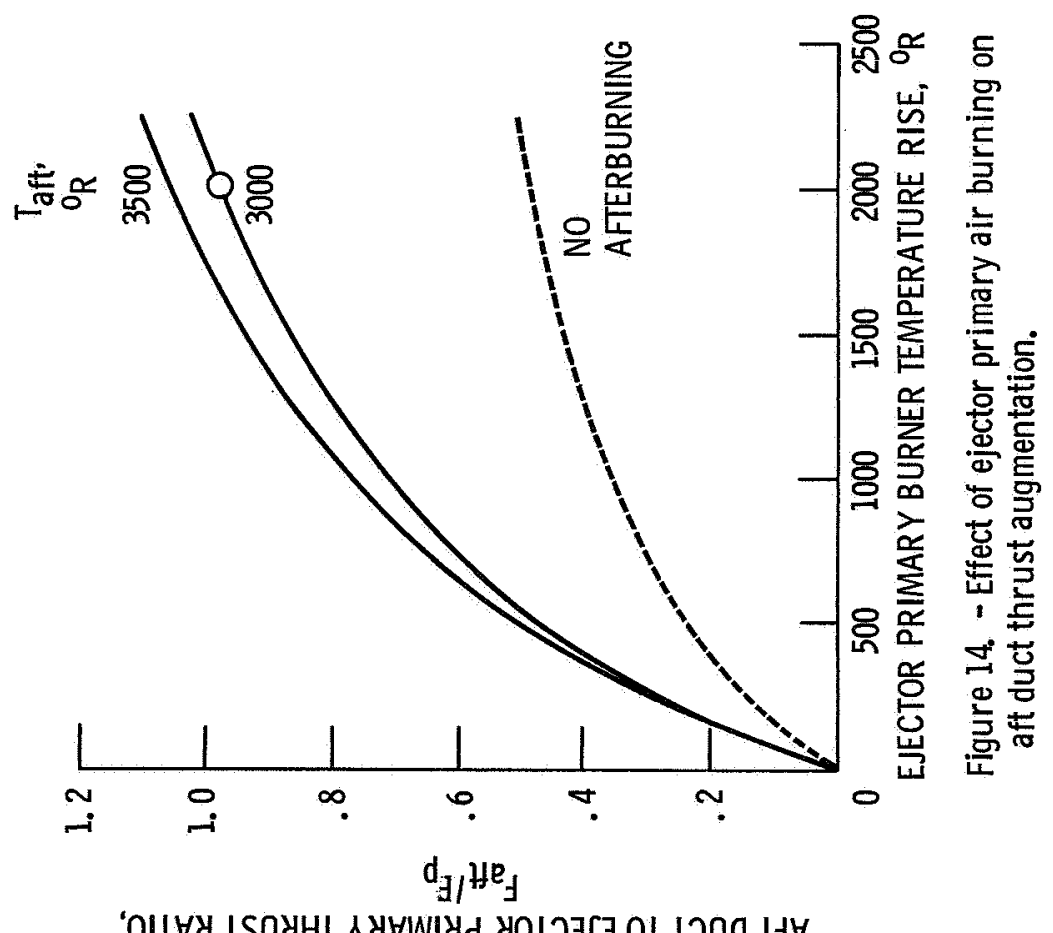

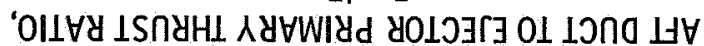




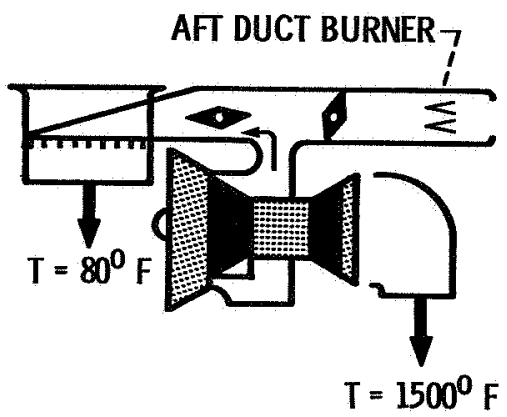

(a) Baseline, cool fan flow to ejector.

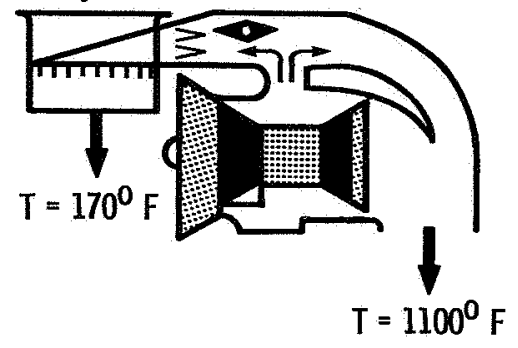

(b) Mixed cool fan and core flows.

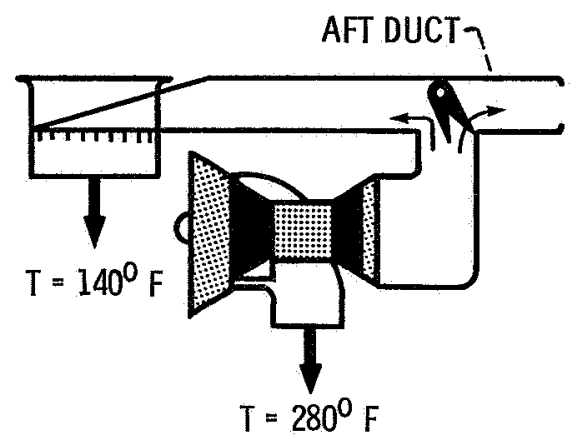

(c) All core flow to ejector

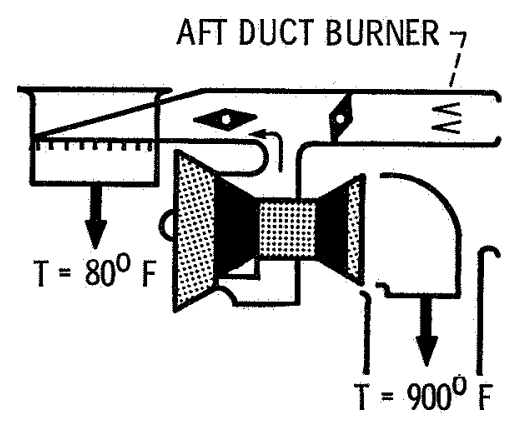

(d) Core flow cooling ejector.

Figure 16. - Exhaust jet cooling options at lift-off conditions. 

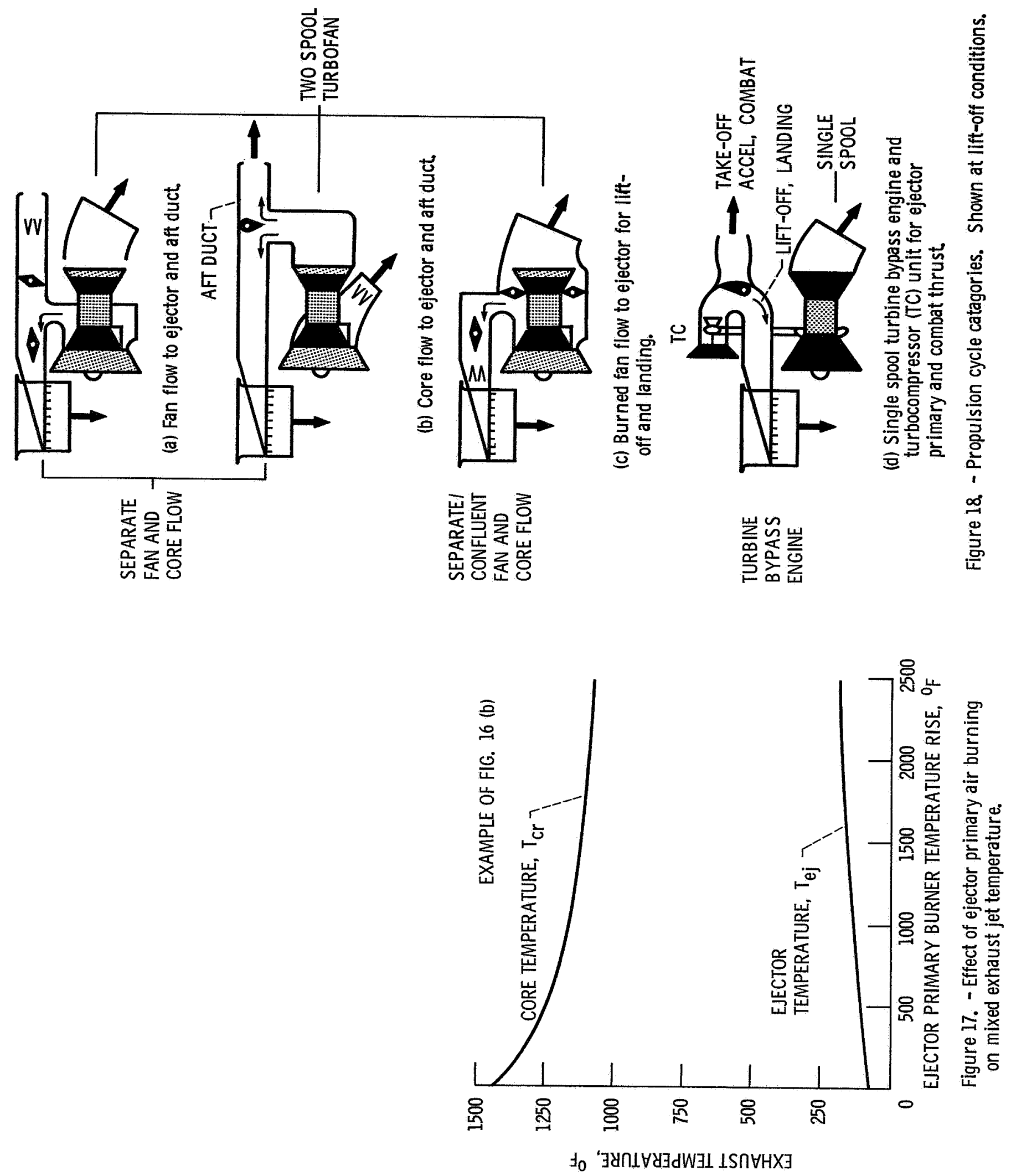


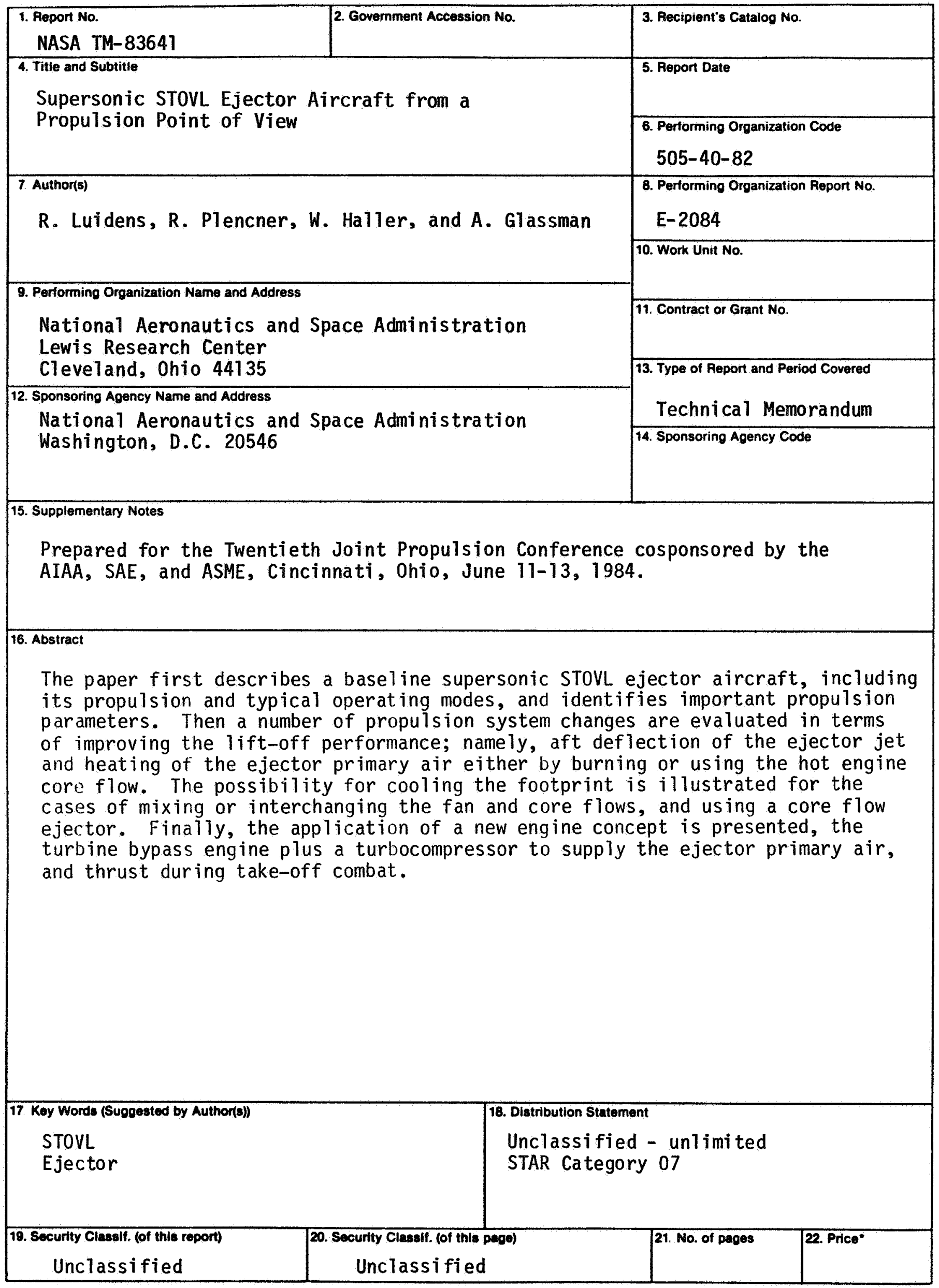

"For sale by the National Technical Information Service, Springfield, Virginia 22161 